Atos de Pesquisa em Educação - ISSN 1809-0354

Blumenau, v.14, n.2, p.359-381, mai./ago. 2019

DOI: http://dx.doi.org/10.7867/1809-0354.2019v14n2p359-381

\title{
INDICADORES DE QUALIDADE DA EDUCAÇÃO SUPERIOR: O PANORAMA DE UMA UNIVERSIDADE COMUNITÁRIA DA REGIÃO OESTE DE SANTA CATARINA
}

\section{HIGHER EDUCATION QUALITY INDICATORS: THE VIEW OF A COMMUNITARIAN UNIVERSITY IN THE WESTERN REGION OF SANTA CATARINA}

\section{INDICADORES DE CALIDAD DE LA EDUCACIÓN SUPERIOR: LA VISIÓN GENERAL DE UNA UNIVERSIDAD COMUNITARIA DE LA REGIÓN OCCIDENTAL DE SANTA CATARINA}

\author{
FOSSÁ, Juliano Luiz \\ j.fossa@unochapeco.edu.br \\ UNOCHAPECÓ - Universidade Comunitária da Região de Chapecó \\ https://orcid.org/0000-0002-9658-4850 \\ PIECZKOWSKI, Tania Mara Zancanaro \\ taniazp@unochapeco.edu.br \\ UNOCHAPECÓ - Universidade Comunitária da Região de Chapecó \\ https://orcid.org/0000-0002-5257-7747
}

\begin{abstract}
RESUMO Realizou-se um estudo de caso cujo objetivo foi analisar o conjunto de indicadores de qualidade da educação superior de uma Instituição Comunitária de Ensino Superior (IES). A questão problematizadora que orientou a elaboração do objetivo geral assim se constituiu: como se apresentaram os indicadores de qualidade da educação superior de uma IES da região oeste de Santa Catarina, no período de 2007 a 2014? Constatamos que o movimento criado pelo Sinaes criou nova cultura de avaliação, com maior envolvimento da academia e busca da qualificação dos cursos. Considerando a importância recebida pela avaliação, é possível fazer dela um elemento propulsor de qualidade da IES, dos cursos e da formação estudantil.
\end{abstract}

Palavras-chave: Avaliação. Indicadores de qualidade. Sinaes.

\begin{abstract}
This is a case study which aimed to analyze the higher education quality indicators set of a higher education institution. The investigative question that guided the development of the overall goal is: How have the higher education quality indicators shown of a higher education institution in the western region of Santa Catarina, from 2007 to 2014? We have noted that the movement made by Sinaes creates new culture, with greater involvement in the qualification courses. Considering the importance received by the evaluation, it is possible to use it as a quality driving element for the institution, the courses and the student training.
\end{abstract}

Keywords: Evaluation. Quality indicators. Sinaes. 
Resumen: Se realizó un estudio de caso para analizar el conjunto de indicadores de calidad de la educación superior de una institución comunitaria de educación superior (IES). La pregunta problemática que guió la elaboración del objetivo general se constituyó de la siguiente manera: ¿Cómo se presentaron los indicadores de calidad de la educación superior de una IES en la región occidental de Santa Catarina de 2007 a 2014? Descubrimos que el movimiento creado por Sinaes creó una nueva cultura de evaluación, con una mayor participación de la academia y la búsqueda de la calificación del curso. Teniendo en cuenta la importancia recibida por la evaluación, es posible convertirla en una fuerza impulsora de calidad de IES, cursos y educación estudiantil.

Palabras clave: evaluación. Indicadores de calidad. Sinaes

\section{INTRODUÇÃO}

O estudo apresentado tem por objetivo analisar o conjunto de indicadores de qualidade da educação superior de uma Instituição Comunitária de Ensino Superior (IES) da região oeste de Santa Catarina, pertencente ao Sistema ACAFE (Associação Catarinense das Fundações Educacionais). Assim, a questão problematizadora orientou a elaboração do objetivo geral e constitui-se em: como se apresentaram os indicadores de qualidade da educação superior de uma IES da região oeste de Santa Catarina, no período de 2007 a 2014?

Embora o estudo tenha sido realizado especificamente em uma IES, a sua realidade a aproxima das demais instituições comunitárias do Sistema ACAFE. Por isso, consideramos que o estudo possa subsidiar outras instituições, não somente o lócus da pesquisa.

A partir da institucionalização do Sistema Nacional de Avaliação (Sinaes), no ano de 2004, com a Lei n. 10.861, a educação superior do País passa a ser avaliada de forma homogênea em todo o território nacional. O Sinaes se constitui estruturalmente em três modalidades de avaliação: (a) Exame Nacional de Desempenho de Estudantes (Enade); (b) Avaliação dos Cursos de Graduação (ACG); (c) Avaliação das instituições de educação superior (Avalies), composta por uma avaliação externa análoga a ACG e pela autoavaliação promovida pelas IES por meio da Comissão Própria de Avaliação (CPA). 


\section{Atos de Pesquisa em Educação - ISSN 1809-0354}

Blumenau, v.14, n.2, p.359-381, mai./ago. 2019

DOI: http://dx.doi.org/10.7867/1809-0354.2019v14n2p359-381

A realização de avaliação presencial dos cursos de graduação (atualmente mais de $31 \mathrm{mil}$ ), no Brasil, apresentou-se nos primeiros anos de implantação do Sinaes como um desafio inviável e moroso, por se tratar de um processo complexo e, principalmente, pela falta de avaliadores capacitados em todas as áreas dos cursos superiores existentes no País.

Em razão dessa inviabilidade e das dificuldades de realização de avaliação presencial no conjunto de cursos de graduação, o Ministério da Educação desenvolveu o Conceito Preliminar de Curso (CPC), que através de indicadores mensura o desempenho de cada curso submetido à avaliação trienal. Os cursos que obtiveram conceitos satisfatórios, ou seja, conceitos 3, 4 e 5 em uma escala de 1 a 5, estão dispensados da avaliação presencial. Com a criação do CPC, em 2007, o número de cursos a serem avaliados presencialmente foi reduzido substancialmente.

O CPC, hoje, é composto por oito indicadores que abrangem o desempenho dos estudantes, medido pelo Exame Nacional de Desempenho de Estudantes (Enade), o Índice de Diferença entre o Desempenho Observado e Esperado (IDD) e insumos do corpo docente coletados do Censo da Educação Superior. Questões como percepção dos estudantes acerca da organização didático-pedagógica, infraestrutura e oportunidades de ampliação da formação são mensuradas por intermédio do questionário socioeconômico e por indicadores do corpo docente (titulação e regime de trabalho).

Esta pesquisa caracteriza-se como um estudo de caso, que envolve aspectos qualitativos e quantitativos, utilizando-se de referências bibliográficas e dados do Ministério da Educação. A escolha pelo estudo de caso é justificada pela investigação estar vinculada a um contexto específico, contudo, sendo os indicadores de qualidade da educação superior válidos a todo o cenário brasileiro, seus resultados podem amparar contextos ampliados.

O texto está estruturado em quatro tópicos: a contextualização conceitual do Sinaes; os procedimentos metodológicos utilizados; análise dos resultados; e, por fim, as considerações finais. 
Atos de Pesquisa em Educação - ISSN 1809-0354

Blumenau, v.14, n.2, p.359-381, mai./ago. 2019

DOI: http://dx.doi.org/10.7867/1809-0354.2019v14n2p359-381

\section{SISTEMA NACIONAL DE AVALIAÇÃO DO ENSINO SUPERIOR (SINAES)}

As primeiras experiências de avaliação no Ensino Superior nos remetem a algumas iniciativas da Coordenação de Aperfeiçoamento de Pessoal de Nível Superior (Capes) no decorrer da década de 1960. Seguem-se as experiências pioneiras da Universidade Estadual de Campinas (UNICAMP) e da Universidade de Brasília (UnB) nos anos 1980 e ao mais amplo e estruturado processo de avaliação institucional desenvolvido nos anos 1990, o Programa de Avaliação Institucional das Universidades Brasileiras - PAIUB (BRASIL, 2004a).

Nos anos de 1970, a pós-graduação, por meio da Capes, ganha evidência. A avaliação na graduação ganha relevância a partir de 1980.

Um dos principais motivadores para a instalação das políticas públicas de avaliação da educação superior no Brasil, como noutros países da América Latina, tem sido a expansão das IES, especialmente a partir de 1990.

O Sinaes foi estabelecido no País com o propósito de organizar os elementos intelectuais orientados por uma lei que garanta as regularidades, coerências e consistências das práticas de avaliação do Ensino Superior (DIAS SOBRINHO, 2004). Para Lacerda e Ferri (2015), o Sinaes estabeleceu cinco aspectos fundamentais: (a) responsabilidade social com a qualidade da educação superior; (b) reconhecimento da diversidade do sistema; (c) o respeito à identidade, à missão e à história das instituições; (d) compreensão de que a instituição deve ser avaliada considerando um conjunto significativo de indicadores de qualidade; (e) continuidade do processo avaliativo.

Segundo Ristoff (2004), a efetiva implantação do sistema deveria se propor a enfrentar desafios estruturais, como: (a) deslocamento de centro de avaliação de uma prova para um conjunto diversificado de instrumentos; (b) integração dos instrumentos de avaliação e de informação e processos avaliativos desenvolvidos por diferentes órgãos do Ministério da Educação e dos sistemas estaduais; (c) valorização dos aspectos qualitativos e interpretativos nos processos e instrumentos; (d) institucionalização de programas permanentes de capacitação de avaliadores; (e) criação e consolidação da cultura de autoavaliação nas Instituições de Ensino Superior; (f) implantação de processos de meta-avaliação. 
O Sinaes, institucionalizado no Brasil, a partir da Lei n. 10.861/2004, teve como principal objetivo assegurar a articulação entre as avaliações internas e externas, por meio de três modalidades: a Autoavaliação; o Enade; e a ACG. (BRASIL, 2004b).

A realização do Enade foi operacionalizada ainda em 2004, quando foi utilizada a experiência e estrutura do extinto Provão. A autoavaliação, da mesma forma, teve seu início juntamente com a implantação do sistema. A maior parte das IES implantou suas CPAs e enviou seus relatórios até o final de 2006 (VERHINE, 2015). Assim, a avaliação externa foi a mais desafiadora, pois a avaliação,

[...] tanto de instituições quanto de cursos, demorou a se concretizar. Avaliadores em grande quantidade precisavam ser capacitados, instrumentos de avaliação tiveram que ser formulados, pré-testados e reformulados, e uma estrutura de logística teve que ser montada de modo a contemplar visitas in loco para todas as instituições e todos os cursos de nível superior que se integram ao sistema federal de educação (VERHINE, 2015, p. 609).

A concepção do Sinaes previa a avaliação externa a todos os cursos superiores do País, contudo, a complexidade e dimensão do Ensino Superior levaram à morosidade e à lentidão do processo de avaliação externa. Essa condição motivou o Ministério da Educação a promover alterações, visando o aperfeiçoamento e melhoria do sistema, culminando na criação do CPC.

A partir das Portarias normativas n. 40/2007 e n. 04/2008 do Ministério da Educação é criado o CPC, o qual determinou que os cursos que atingissem desempenho satisfatório ficariam dispensados da avaliação in loco para os processos de reconhecimento de curso (BRASIL, 2007; 2008). Com a constituição do CPC, equacionou-se (pelo menos em parte) a morosidade e se estabeleceu uma dinâmica sistemática capaz de atender, via avaliação externa, os cursos que não atingiram o desempenho mínimo aceitável no CPC.

O CPC se constituiu, a partir de 2008, clara e objetivamente no principal indicador de qualidade do Ensino Superior, inclusive, atrelado às questões regulatórias e demais políticas públicas de acesso e permanência na educação superior. Esse indicador origina-se fundamentalmente do Enade e do Censo da Educação Superior. Ainda compõem como indicadores constituintes do CPC: "Aspectos relacionados à infraestrutura e à organização didático-pedagógica dos 
DOI: http://dx.doi.org/10.7867/1809-0354.2019v14n2p359-381

cursos, que constam nos instrumentos de avaliação do Inep [...]" (LACERDA; FERRI, 2015, p. 132).

A partir do ano de 2007, o Instituto Nacional de Estudos e Pesquisas Educacionais Anísio Teixeira (INEP), por meio da Diretoria de Avaliação do Ensino Superior, publicou a primeira nota técnica que estabeleceu os procedimentos de cálculo do CPC. Desde então, o CPC passou por diversas modificações, tendo sido publicadas notas técnicas anuais. Atualmente, o indicador é composto por oito componentes, relacionados a seguir:

- Nota do Concluinte no Exame Nacional de Desempenho de Estudantes (NC);

- Nota do Indicador da Diferença entre os Desempenhos Observado e Esperado (NIDD);

- Nota referente à organização didático-pedagógica (NO);

- Nota referente à infraestrutura e instalações físicas (NF);

- Nota referente às oportunidades de ampliação da formação acadêmica e Profissional (NA);

- Nota de Proporção de Mestres (NM);

- Nota de Proporção de Doutores (ND);

- Nota de Regime de Trabalho (NR).

A composição percentual dos indicadores do CPC está distribuída da seguinte maneira: Nota do Concluinte no Enade (20,0\%); Nota do IDD (35,0\%); Nota referente à organização didática pedagógica (7,5\%); Nota referente à infraestrutura e instalações físicas (5,0\%); Nota referente às oportunidades de ampliação da formação acadêmica e Profissional (2,5\%); Nota de Proporção de Mestres (7,5\%); Nota de Proporção de Doutores (15,0\%); Nota de Regime de Trabalho $(7,5 \%)$ (BRASIL, 2015).

Essa composição resulta na seguinte fórmula de cálculo:

$$
\begin{gathered}
C P C=(N C x 0,20)+(N I D D x 0,35)+(N O x 0,075)+(N I x 0,05)+(N A x 0,025) \\
+(N M x 0,075)+(N D x 0,15)+(N R x 0,075)
\end{gathered}
$$


Estes indicadores recebem tratamentos estatísticos (padronização) e seus resultados assumem valores contínuos entre 0 e 5 , que são enquadrados em faixas para definição do conceito de curso, conforme é demonstrado na Tabela 1.

Tabela 1: Parâmetros de conversão de NC em CPC.

\begin{tabular}{c|c}
\hline CPC (Valor contínuo) & CPC (Faixa) \\
\hline $0 \leq \mathrm{a}<0,945$ & 1 \\
$0,945 \leq \mathrm{a}<1,945$ & 2 \\
$1,945 \leq \mathrm{a}<2,945$ & 3 \\
$2,945 \leq \mathrm{a}<3,945$ & 4 \\
$3,945 \leq \mathrm{a} \leq 5$ & 5 \\
\hline
\end{tabular}

Fonte: Brasil (2015).

O desempenho mínimo satisfatório é o conceito 3 , ou seja, o curso deve atingir pelo menos o valor contínuo acima de 1,945. Os cursos que atingirem os conceitos 1 e 2 são considerados com desempenhos insatisfatórios. Já os cursos com conceitos 4 e 5 são considerados com desempenho acima da média.

Os cursos de graduação são agrupados por área de avaliação do Enade e para cada área, separadamente, são constituídos os CPCs do conjunto de cursos. Os procedimentos metodológicos dos cálculos matemáticos direcionam para uma distribuição normal entre os conceitos dos cursos de uma determinada área. Isso significa que os resultados de cada curso de graduação são determinados pelos resultados (indicadores) dos demais cursos que compõem a mesma área. Teoricamente, em todas as áreas de avaliação do Enade haverá cursos com conceitos 1 e 2, cursos com conceito 3 (maior parte) e cursos com conceitos 4 e 5 .

$\mathrm{O}$ conjunto de indicadores que compõem o CPC é uma articulação que aglutina em torno de um indicador os aspectos de desempenho dos estudantes, suas percepções sobre e processo formativo e as características do corpo docente. Nesse curto período, na instituição em análise, o CPC tornou-se o principal indicador de qualidade da educação superior, especialmente por seus vínculos aos processos de políticas regulatórias.

\section{CAMINHO METODOLÓGICO}




\section{Atos de Pesquisa em Educação - ISSN 1809-0354}

Blumenau, v.14, n.2, p.359-381, mai./ago. 2019

DOI: http://dx.doi.org/10.7867/1809-0354.2019v14n2p359-381

Meyer e Paraíso ressaltam que a metodologia de construção da pesquisa é composta por um "[...] certo modo de perguntar, de interrogar, de formular questões e de construir problemas de pesquisa que é articulado a um conjunto de procedimentos de coleta de informações [...]" (MEYER; PARAíSO, 2012, p. 16).

Sobre a metodologia, Minayo (2012, p. 300) afirma que "[...] métodos e instrumentos são caminhos mediadores para permitir ao pesquisador o aprofundamento de sua pergunta central e suas perguntas sucessivas, levantadas a partir do encontro com seu objeto empírico ou documental". A aproximação com a realidade (mediada pela pesquisa e seus procedimentos metodológicos) leva a produzir conhecimentos a partir de experiências em diferentes espaços e contextos sócio-históricos. Em se tratando do conhecimento científico, esse aperfeiçoa o uso da racionalidade ao propor uma forma sistemática, metódica e crítica de desvelar e explicar a realidade (KÖCHE, 2002).

Este estudo apresenta-se como de caso em caráter misto, configurando-se nas abordagens qualitativa e quantitativa, e se apoia no levantamento bibliográfico, levando em conta: (a) levantamento de referências; (b) leituras; (c) registro das informações; (d) e a estruturação escrita do texto, o que, para Dmitruk (2012, p. 47), "[...] consiste num conjunto sequencial de procedimentos planejados para recolher, analisar e sintetizar as principais contribuições teóricas sobre um assunto, assim como para elaborar um texto escrito sobre um objeto de estudo." Apoia-se, também, em fontes de dados e informações públicas, via on-line, a partir do sítio eletrônico do Ministério da Educação e Cultura, via INEP.

Como delimitação de estudo, foram analisados os indicadores de qualidade da educação superior, medidos e resultantes do Enade de uma instituição comunitária da região oeste de Santa Catarina, contemplando o período de 2007 a 2014. A análise dos dados foi por meio da observação das frequências simples e da escala de mensuração das notas padronizadas.

Os indicadores de qualidades observados neste estudo condizem com os estabelecidos pelo Sinaes e se constituem em: (a) Nota do Concluinte no Exame Nacional de Desempenho de Estudantes (NC); (b) Nota do Indicador da Diferença entre os Desempenhos Observado e Esperado (NIDD); (c) Nota referente à organização didático-pedagógica (NO); (d) Nota referente à infraestrutura e 
DOI: http://dx.doi.org/10.7867/1809-0354.2019v14n2p359-381

instalações físicas (NF); (e) Nota referente às oportunidades de ampliação da formação acadêmica e Profissional (NA); (f) Nota de Proporção de Mestres (NM); (g) Nota de Proporção de Doutores (NM); (h) Nota de Regime de Trabalho (NR).

\section{ANÁLISE DE RESULTADOS}

No período de 2007 a 2014, a Universidade em estudo teve 90 participações na avaliação trienal (Enade e CPC). Ao todo foram 43 cursos distintos avaliados, desenvolvidos em sua maioria no Campus Sede e nas duas unidades fora, em municípios da região. Desse total, 31 são cursos de bacharelado e 10 são cursos de licenciatura. No Gráfico 1 constam as quantidades de cursos, por ano, que passaram pela avaliação trienal nessa instituição.

Gráfico 1: Número de cursos participantes de uma IES na avaliação trienal no período de 2007 a 2014.

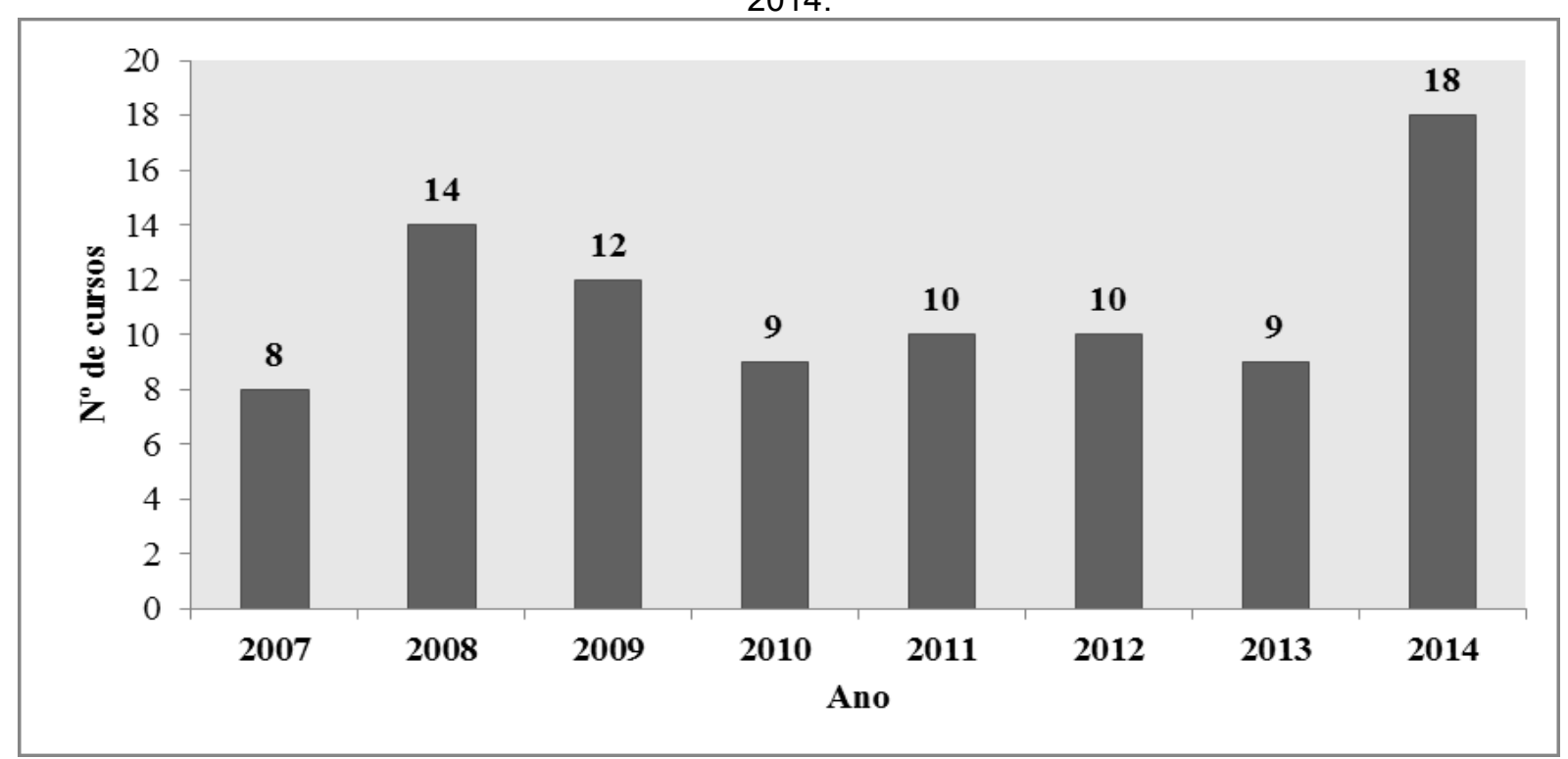

Fonte: Elaboração do primeiro autor (2016), a partir de dados do INEP.

Ao longo desse período, em apenas 11 casos não houve a divulgação do CPC, que, de acordo com os ordenamentos legais do Ministério da Educação, ocorrem por dois motivos: pela ausência de algum indicador do curso que compõe o CPC ou se na data de divulgação do CPC o curso ainda não estiver reconhecido. $O$ panorama da IES pesquisada neste estudo apresenta sete situações pelo primeiro e outras quatro pelo segundo motivo. 
DOI: http://dx.doi.org/10.7867/1809-0354.2019v14n2p359-381

Para a sequência das análises foram excluídos os 11 casos que não apresentaram CPC no período, além de outros três casos que, apesar de possuírem CPC, não tiveram os valores do IDD divulgado. Dessa forma, restaram 76 cursos (unidades) com indicadores, em que a análise de cada indicador foi realizada de forma individual. Na sequência, são apresentados os indicadores e uma breve contextualização de cada um.

- Oportunidades de ampliação da formação acadêmica e Profissional: Este indicador é o mais recente, implantado no ciclo avaliativo de 2013, e leva em consideração a percepção do estudante quanto às oportunidades oferecidas pela IES, relativa à ampliação de formação acadêmica. Sua mensuração é realizada a partir de 6 tópicos do questionário socioeconômico do estudante participante do Enade.

Este indicador foi apurado em 25 unidades, e em todos os casos registrou valor contínuo superior a 1,945, ou seja, em todos os cursos este indicador apresentou valores contínuos equivalentes ou superiores ao conceito 3 , em que em 18 casos $(72,0 \%)$ o enquadramento está na faixa 4 ou 5 . Na média, o valor foi de 3,48 e o desvio padrão de 0,74 , de forma que o menor valor foi 2,35 e o maior igual a 5. Neste indicador a IES apresenta desempenho plenamente satisfatório.

- Infraestrutura e instalações físicas: Até o ano de 2012 este indicador era mensurado a partir de uma única pergunta do questionário socioeconômico do estudante participante do Enade. Em 2013 e 2014, o INEP modificou este indicador, que passa a ser medido por 12 perguntas do referido instrumento. As respostas também se constituem na percepção dos estudantes, a partir de suas experiências ao longo de sua trajetória no curso.

Em todas as 76 ocasiões em que os cursos da instituição pesquisada apresentaram CPC, o indicador das questões relacionadas à infraestrutura foi mensurado. Assim como no indicador anterior, as percepções dos estudantes, da IES em estudo, em sua ampla maioria, avaliaram as questões de infraestrutura de forma positiva. Entre os 76 registros, 67 avaliaram estas questões com valores acima da média, ou seja, valores que resultariam, neste indicador, em conceito 4 ou 5. Com conceito 3 (desempenho satisfatório) houve oito registros no período, e com conceito 2 apenas um registro. No ano de 2009, somente um curso, neste quesito, obteve conceito 4 no CPC. 


\section{Atos de Pesquisa em Educação - ISSN 1809-0354}

\section{Blumenau, v.14, n.2, p.359-381, mai./ago. 2019}

DOI: http://dx.doi.org/10.7867/1809-0354.2019v14n2p359-381

- Nota referente à organização didático-pedagógica: Este indicador também está presente em toda série histórica (2007-2014), da mesma forma como o indicador referente à infraestrutura. Até o ano de 2012 era mensurado apenas por uma única questão e nos anos de 2013 e 2014 passou a ser mensurado por 23 questões, tornando este indicador mais amplo e complexo.

Os valores analisados apontam para um desempenho positivo também neste indicador, pois, dos 76 registros, 56 se apresentam acima 2,945, configurando-se em conceito 4 ou 5 . No entanto, em 16 registros, essa métrica representou conceito 3 e outros quatro registros em conceito 2 . É importante ressaltar que os quatro registros que obtiveram valores cujo enquadramento é o conceito 2 ocorreram nos anos de 2013 e 2014. Além disso, dos 16 registros com conceito 3, 14 destes foram avaliados igualmente nos anos de 2013 e 2014.

A partir disso, percebemos que, especialmente nos últimos dois anos (2013/2014), o indicador da organização didático-pedagógica, segundo a percepção dos estudantes dessa IES, teve indicadores menores em relação aos demais anos. Essa avaliação moderada nos últimos dois anos pode estar diretamente associada à mudança do instrumento e metodologia do referido indicador.

- Nota de Regime de Trabalho: O indicador referente ao regime de trabalho do corpo docente é calculado a partir das informações do Censo da Educação Superior para cada curso. Dessa forma, são computados os docentes pertencentes ao curso que atuam em regime parcial e integral no ano em que o curso participa da avaliação trienal ${ }^{1}$.

Neste indicador, a IES apresentou desempenho amplamente positivo. Em 74 $(97,37 \%)$ dos registros, os valores representam conceito 4 ou 5 , em que em 55 $(72,36 \%)$ este enquadramento refere-se ao conceito 5 . Os dois cursos que se enquadram no conceito 2 foram registrados em 2009 e 2014. O primeiro, em um curso de tecnologia; o segundo, em um curso de licenciatura em convênio com o Parfor.

- Nota de Proporção de Mestres: Neste indicador é calculada a nota de cada curso a partir da proporção de docentes com titulação mínima de mestrado (docentes com

\footnotetext{
1 Os conceitos e regras de enquadramento regime de trabalho, conforme Portaria Normativa MEC 40/2007.
} 
DOI: http://dx.doi.org/10.7867/1809-0354.2019v14n2p359-381

titulação de doutorado também são incluídos). Os insumos são oriundos do Censo da Educação Superior.

Em 2007, primeiro ano de divulgação dos indicadores do CPC, a proporção de docentes com titulação não constava na relação dos indicadores, desta forma, para esta análise foram computados os valores no período de 2008 a 2014. Nestes sete anos, foram 72 registros, com valores contínuos, variando desde 0,56 até o valor máximo de 5,00. O Gráfico 2 apresenta a distribuição destes valores conforme as faixas de enquadramento do CPC.

A IES apresentou, no período, sete valores abaixo do limite estabelecido como desempenho mínimo, ou seja, conceitos 1 e 2, representando 9,7\% do total. $\mathrm{Na}$ faixa do conceito 3, padrão mínimo aceitável como de qualidade, foram vinte registros, significando o percentual de $27,78 \%$. Na faixa dos conceitos 4 e 5 foram 45 dos registros, representando $62,5 \%$ do total.

Gráfico 2: Distribuição dos valores contínuos do indicador proporção de docentes mestres por faixa do CPC, período de 2008 a 2014.

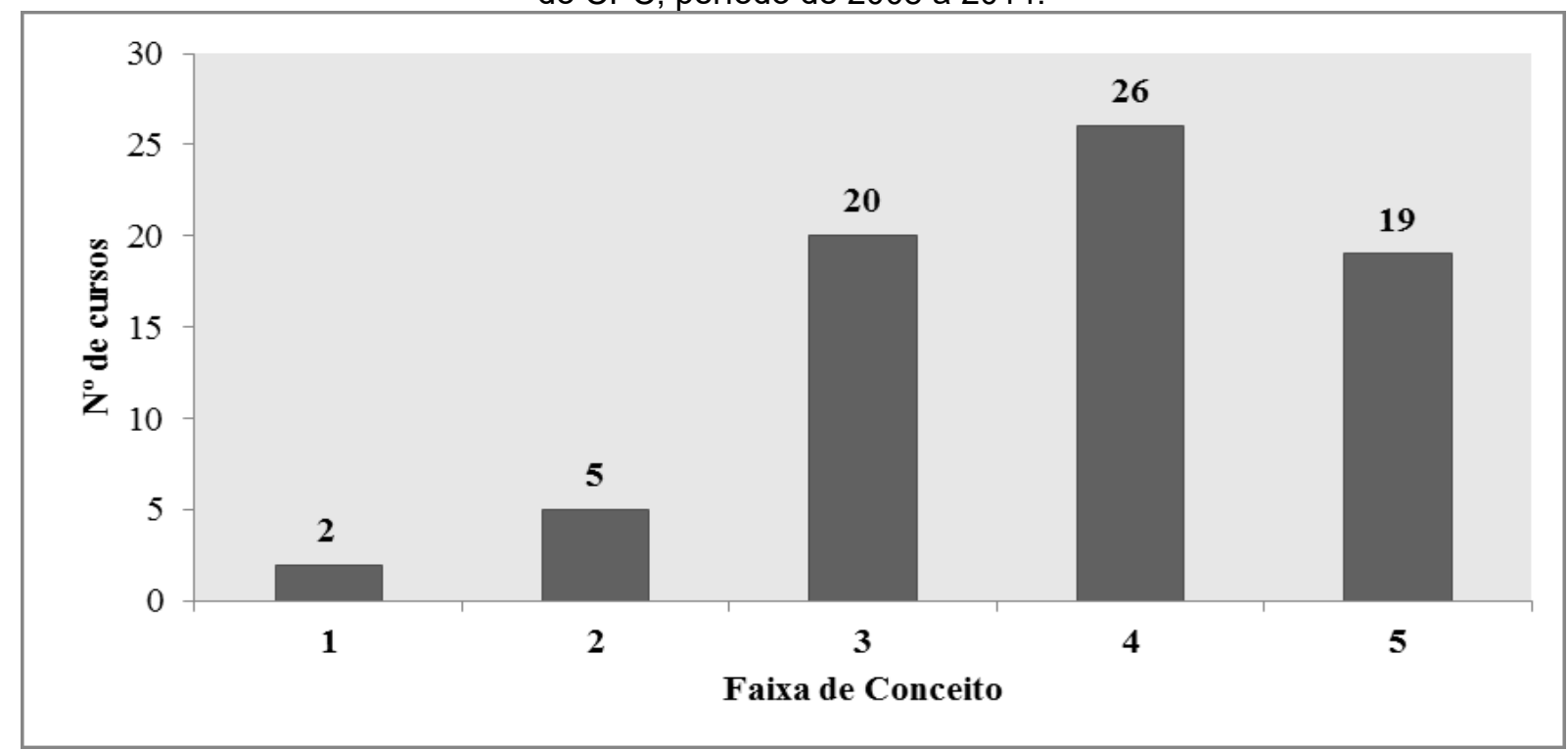

Fonte: Elaboração do primeiro autor (2016), a partir de dados do INEP.

Em linhas gerais, neste indicador, a IES apresenta bom desempenho, pois a maior parte dos valores posiciona-se acima da média (conceito 3). Contudo, ao longo do período não se percebe uma melhoria no comportamento destes indicadores ${ }^{2}$.

\footnotetext{
${ }^{2}$ Conjuntos de indicadores disponíveis em: <www.inep.gov.br>.
} 


\section{Atos de Pesquisa em Educação - ISSN 1809-0354}

\section{Blumenau, v.14, n.2, p.359-381, mai./ago. 2019}

DOI: http://dx.doi.org/10.7867/1809-0354.2019v14n2p359-381

- Nota de Proporção de Doutores: Os resultados deste indicador, assim como dos indicadores referentes ao regime de trabalho docente e a proporção de docentes com no mínimo titulação de mestrado, são obtidos a partir do Censo da Educação Superior. Este indicador, dentre o conjunto de componentes do CPC, representa a maior fragilidade da IES pesquisada.

No total dos 76 registros, em 72 , ou seja, em $94,74 \%$, o enquadramento dos valores contínuos foi nas faixas de conceito 1 e 2 . Nos demais quatro registros, os valores referem-se ao conceito 3. No ciclo avaliativo de 2012/2013/2014 foram avaliados 35 cursos na IES e somente o curso (Ciências Biológicas - Bacharelado) alcançou valor contínuo acima de 1,945 neste indicador.

Gráfico 3: Distribuição percentual dos valores contínuos do indicador proporção de docentes doutores por faixa do CPC, período de 2007 a 2014.

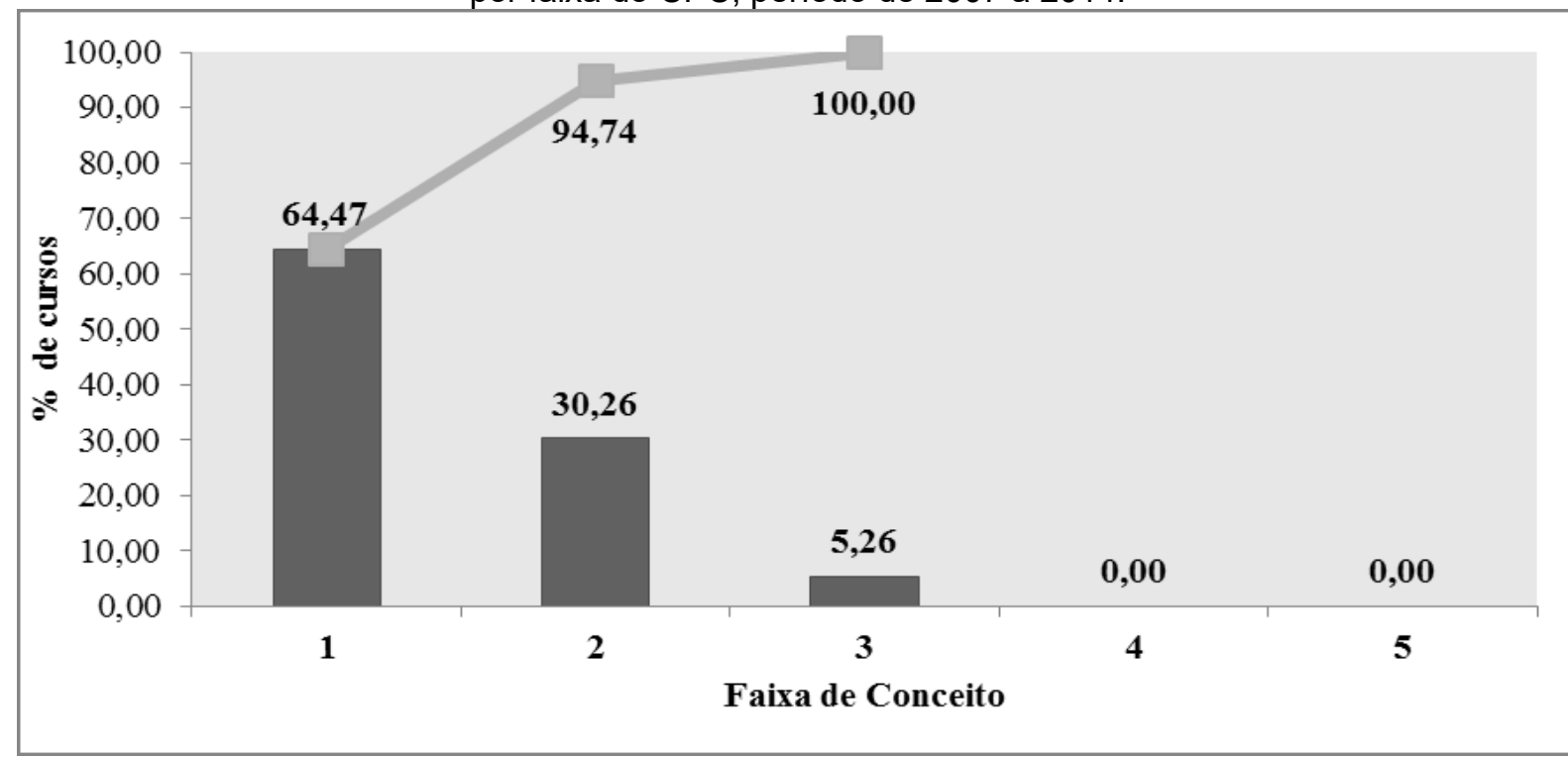

Fonte: Elaboração do primeiro autor (2016), a partir de dados do INEP.

O conjunto de valores apresentados neste indicador fragiliza significativamente o desempenho dos cursos, especialmente no que diz respeito à expressão deste indicador na composição do CPC. Percebe-se também que no decorrer dos anos compreendidos nesta análise não houve alterações significativas acerca da melhoria deste componente do cálculo.

- Nota do Indicador da Diferença entre os Desempenhos Observado e Esperado: Em linhas gerais, o IDD procura medir as diferenças de desempenho dos estudantes ingressantes e concluintes. A partir de 2011, a comparação entre os desempenhos 


\section{Atos de Pesquisa em Educação - ISSN 1809-0354}

\section{Blumenau, v.14, n.2, p.359-381, mai./ago. 2019}

DOI: http://dx.doi.org/10.7867/1809-0354.2019v14n2p359-381

ocorre entre as notas do Exame Nacional do Ensino Médio (ENEM) e os concluintes participantes do Enade. Anteriormente a esse período, os ingressantes também participavam da prova do Enade. Além disso, outros indicadores são utilizados para realização do cálculo deste indicador ${ }^{3}$.

Os resultados da IES neste importante indicador apresentam o quanto o curso superior agregou conhecimentos aos estudantes. No entanto, no período em análise foram $13(17,11 \%)$ registros abaixo da faixa mínima esperada, ou seja, abaixo do valor de 1,945. Dessa forma, a maior parte dos valores alcançados foi nos conceitos 3 , 4, e 5 , em que 27 foram no conceito 3,28 no conceito 4 e sete no conceito 5 . O percentual de $46,05 \%$ dos registros foi nos dois conceitos mais altos (4 e 5), o que demonstra que significativa parte dos cursos da IES estão agregando conhecimento acima da média aos seus egressos.

- Nota do Concluinte no Exame Nacional de Desempenho de Estudantes: Este indicador é medido a partir do desempenho dos concluintes na prova do Enade, que contempla questões de formação geral e conhecimentos específicos.

Foram computados no período em análise 76 registros de nota do Enade na IES, distribuídos conforme as faixas de enquadramento da seguinte maneira: (a) conceito 1, 1 curso; (b) conceito 2, 18 cursos; (c) conceito 3, 47 cursos; (d) conceito 4, 9 cursos; (e) conceito 5, 1 curso. Os conceitos 1 e 2 acumularam $25 \%$ do total de resultados, o conceito 3 representou $61,84 \%$ e, por fim, os conceitos 4 e 5 somaram $13,16 \%$.

\footnotetext{
${ }^{3}$ Detalhamento dos insumos disponível em: <www.inep.gov.br>.
} 
DOI: http://dx.doi.org/10.7867/1809-0354.2019v14n2p359-381

Gráfico 4: Distribuição dos valores contínuos do indicador Enade por faixa do CPC, período de 2007 a 2014.

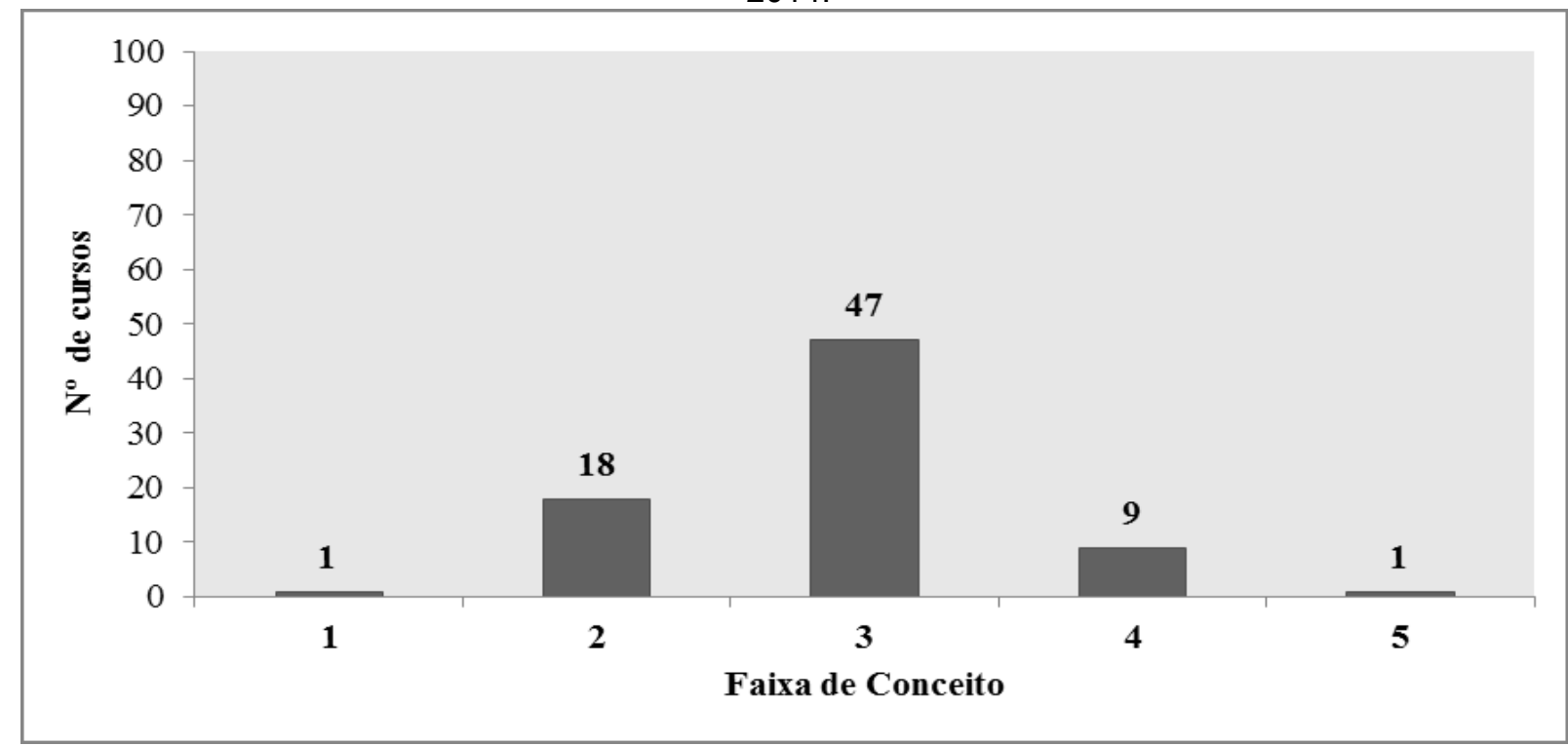

Fonte: Elaboração do primeiro autor (2016), a partir de dados do INEP.

Apesar de a maior parcela dos cursos apresentar conceito 3, registra-se que $1 / 4$ dos conceitos, no período, ficaram abaixo do desempenho mínimo de qualidade esperado. Registra-se, também, que o desempenho médio entre os cursos na comparação do ciclo avaliativo 2009/2010/2011 e 2012/2013/2014 teve ligeira redução. No ciclo verde (2010 e 2013) passou de 2,36 para 2,32, no ciclo azul (2011 e 2014 ) de 2,41 para 2,12 e no ciclo vermelho (2009 e 2012) de 2,74 para 2,35. No último ciclo avaliativo, 35 cursos obtiveram conceito no Enade.

Destes, apenas 3 cursos alcançaram o conceito 4. Por outro lado, 11 cursos ficaram na faixa do conceito 1 e 2, em que no ano de 2014, dos 16 cursos avaliados, 7 apresentaram resultados abaixo do conceito 3.

- Conceito Preliminar de Curso (CPC): O detalhamento do conjunto dos oito indicadores que compõem os insumos para cálculo do CPC determina os conceitos deste indicador, e como resultado dessa fórmula, a IES, nesse período, apresentou a seguinte distribuição dos conceitos, conforme Gráfico 5.

O total de cursos avaliados com CPCs abaixo do desempenho mínimo esperado foi igual a 7 , representando $9,21 \%$ do total. Os cursos que ficaram com desempenho médio, no período, resultaram 48 registros $(63,16 \%)$, enquanto os cursos com registros no conceito 4 se apresentaram, neste conceito, em 21 ocasiões, significando 27,63\% do total. Não houve entre 2007 e 2014 ocasiões em 
DOI: http://dx.doi.org/10.7867/1809-0354.2019v14n2p359-381

que os cursos avaliados obtivessem conceitos 1 e 5 , ou seja, conceito mínimo e máximo, respectivamente.

Gráfico 5 - Distribuição dos conceitos por faixa do CPC, período de 2007 a 2014.

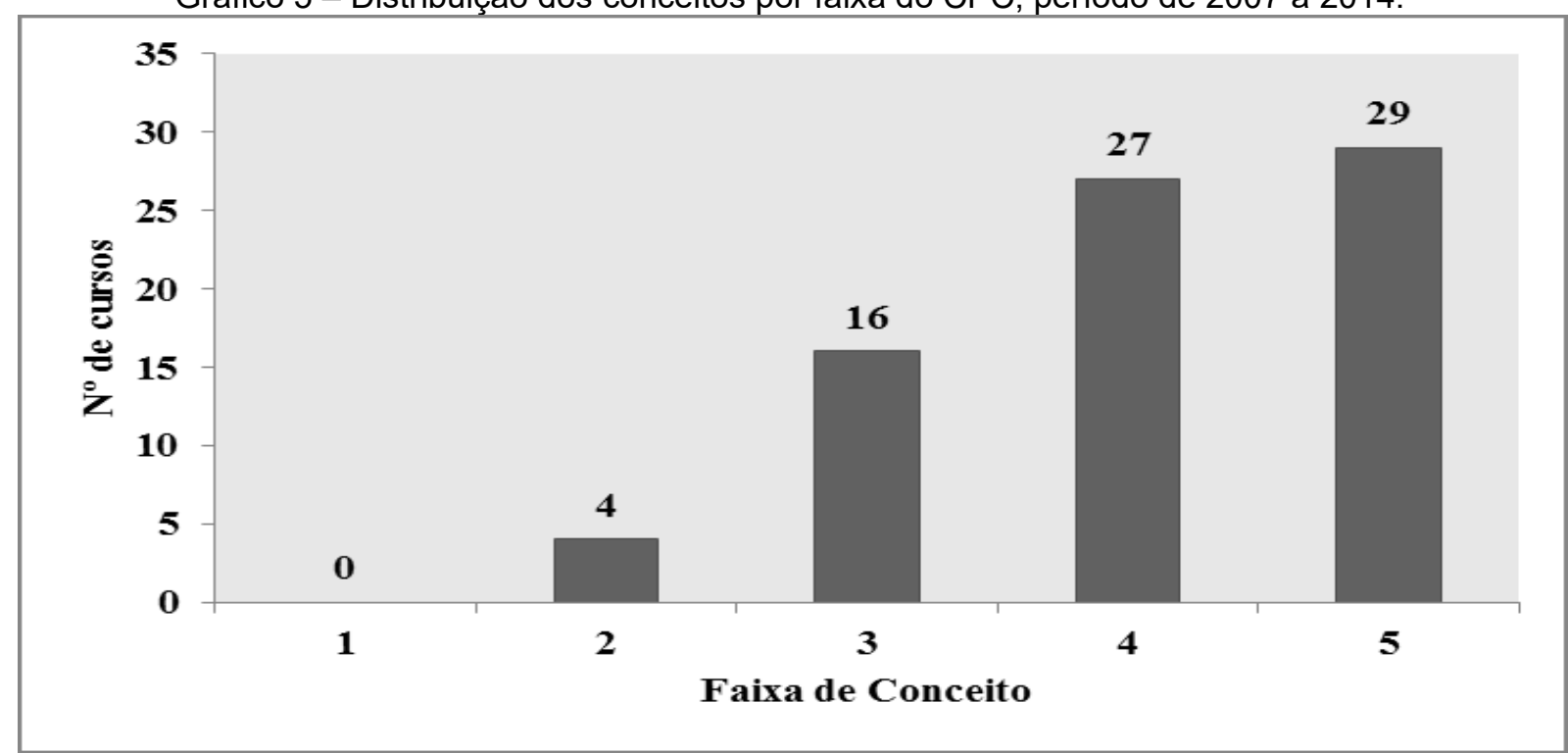

Fonte: Elaboração do primeiro autor (2016), a partir de dados do INEP.

Os valores dos CPCs dos cursos, em cada ano, somados aos conceitos dos programas Stricto Sensu (Mestrado e Doutorado), determinam o Índice Geral de Cursos (IGC), ou seja, o índice geral de qualidade da IES como um todo. A instituição em estudo até o ano de 2014 não possuía nenhum programa de doutorado e todos os seus programas de mestrado possuíam o conceito mínimo (conceito 3) para funcionamento dos programas, conforme determina a Capes. Em todo o período analisado, o conceito médio da pós-graduação Stricto Sensu foi igual a 3. As variações no IGC foram exclusivamente determinadas pelo desempenho da graduação através dos CPCs.

Nesse período, o IGC da IES em análise apresentou queda no indicador no período de 2007 até 2010, passando de 2,70 para 2,50. Recuperou-se a partir de 2011, em que em 2013 o valor do indicador foi de 2,65, e em 2014 teve leve queda para 2,62. Na sequência, o Gráfico 6 evidencia o desempenho obtido pela IES. 
Atos de Pesquisa em Educação - ISSN 1809-0354

Blumenau, v.14, n.2, p.359-381, mai./ago. 2019

DOI: http://dx.doi.org/10.7867/1809-0354.2019v14n2p359-381

Gráfico 6: Distribuição dos conceitos do IGC por ano, período de 2007 a 2014.

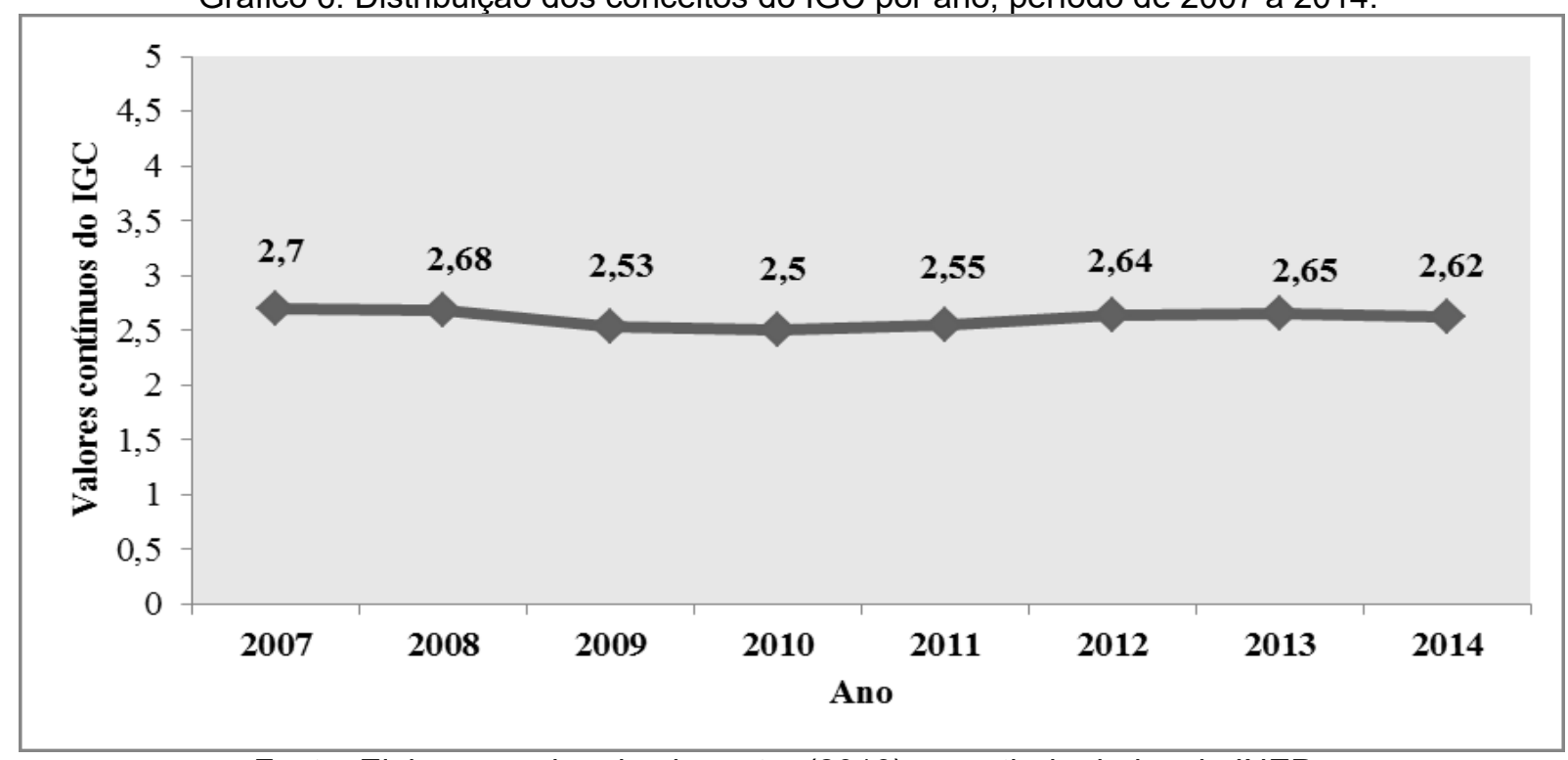

Fonte: Elaboração do primeiro autor (2016), a partir de dados do INEP.

Esse resultado pode ser explicado, principalmente, pelos baixos índices referentes à proporção de professores doutores nos cursos da IES e pela queda no rendimento no desempenho na prova do Enade, especialmente, no ciclo avaliativo de 2012/2013/2014. Nos demais indicadores, a IES apresenta bons resultados, no entanto, como este índice leva em consideração os demais cursos em cada área, é necessário empreender esforços para que, em médio prazo, a IES consiga alcançar melhores indicadores em relação aos demais cursos e IES que constituem o sistema de Ensino Superior no País.

O item relativo ao número reduzido de doutores na universidade pesquisada pode ser compreendido, em parte, em razão da localização geográfica, considerando que, ainda neste ano de 2017, o curso mais próximo de doutorado em educação, por exemplo, localiza-se num raio de $500 \mathrm{~km}$. Com outros cursos de doutoramento não é diferente, o que limita a busca pela titulação.

O baixo desempenho nas provas do Enade merece cuidados e análises aprofundadas. Não é incomum a queixa dos professores no sentido de que os estudantes apresentam dificuldades básicas de compreensão de textos, de interpretação, escrita, cálculo, entre outras. Alguns reagem com certo saudosismo, referindo que "antigamente" os estudantes eram mais "preparados", mais "disciplinados", mais "selecionados", entre outras justificativas. 


\section{Atos de Pesquisa em Educação - ISSN 1809-0354}

Blumenau, v.14, n.2, p.359-381, mai./ago. 2019

DOI: http://dx.doi.org/10.7867/1809-0354.2019v14n2p359-381

Nós acreditamos que a expansão do número de vagas na educação superior, neste século, contribuiu para a democratização da educação e, ao assumi-la, precisamos assumir também as mudanças inerentes e os desdobramentos históricos dela decorrentes.

Embora sejam reconhecidas essas fragilidades na formação básica dos estudantes, a universidade possui grande relevância no contexto educacional e precisa assumir seu papel social ao receber jovens com importantes lacunas na formação e promover a mudança. Pieczkowski $(2014$, p. 66) afirma

[...] que não podemos negar as diferenças que se revelam na universidade, nem culpabilizar vítimas e naturalizar a seleção e a exclusão. A pluralidade de estudantes ingressantes na universidade demanda das docentes novas posturas, reavaliação das metodologias, desconstruindo a ideia de estudantes universais para os quais currículos fixos e estagnados são válidos.

A universidade representa um espaço importante para a construção de conhecimentos e também relações interpessoais baseadas na ética e no respeito às diferenças.

Os aspectos regulatórios do Sinaes (CPC e IGC) ganharam maior relevância que os aspectos avaliativos, como Conceito de Curso (CC) e Conceito Institucional $(\mathrm{Cl})$. Isso gera uma supervalorização do Enade, que ganha evidência em relação ao sistema na sua amplitude.

Corrêa e Ferri (2017, p. 90), com as quais concordamos, salientam que afirmar que os conceitos e indicadores mencionados "garantem a qualidade seria tratar de forma reducionista um assunto tão complexo". Embora o resultado do exame, a infraestrutura, a titulação e o regime de trabalho docente sejam indicadores significativos, não revelam a sala de aula, a relação professor-estudante, a mediação pedagógica, os processos de ensino e aprendizagem, que são fatores relevantes para a qualidade de um curso.

\section{CONSIDERAÇÕES FINAIS}


DOI: http://dx.doi.org/10.7867/1809-0354.2019v14n2p359-381

Constatamos que as IES, no Brasil, na contemporaneidade, são avaliadas, reguladas e classificadas de acordo com o Sinaes. Esse movimento cria novas culturas, com maior envolvimento na busca da qualificação dos cursos e das IES.

As instituições que não cumprem seu papel, aos olhos do Estado, são punidas com cursos desativados ou vagas reduzidas. Os docentes e estudantes que integram as instituições também vivem as consequências da avaliação. Diante de uma avaliação negativa no critério da titulação docente, por exemplo, podem ocorrer não contratações ou mesmo demissões de quem não possui titulação de mestre e doutor, uma vez que a titulação é um elemento a ser recompensado, na perspectiva da política avaliativa. Diante de um curso com baixa avaliação os estudantes também podem ser penalizados, uma vez que o Fundo de Financiamento Estudantil (FIES) não é acessado por estudantes vinculados a cursos avaliados com conceito inferior a 3. O reconhecimento social das IES também é fortalecido diante de boas avaliações, ou abalado, considerando que os resultados repercutem nas mídias e, cada vez mais, a sociedade consulta esses resultados para escolher os cursos de graduação ou pós-graduação. Até mesmo alguns empregadores consultam o curso do candidato a uma vaga de trabalho, analisando o desempenho junto ao Enade.

Defendemos que a avaliação e a regulação são necessárias e salutares, se considerarmos a educação como um bem público. Contudo, o estudo evidencia as fragilidades de uma universidade comunitária, localizada no interior de um país com território vasto e com tanta diversidade cultural, em atender aos imperativos do Sinaes. Concordamos com Machado (2017, p. 13), quando afirma que

[...] o Sinaes está impregnado de valor, toma a universidade pública federal como modelo de qualidade e estabelece um enorme conjunto de variáveis para atestar esse posicionamento. Assim, o processo de avaliação aplica esse molde sobre as instituições de ensino superior das mais diferentes regiões, portes e enquadramentos, para chegar à óbvia constatação de que as universidades públicas federais ocupam o topo dos rankings, e as demais ficam em situações intermediárias, com fortes limitações para atingir a apregoada qualidade. É como o sapato de cristal da cinderela, que vai caber apenas no pé para o qual foi concebido ou outros à sua semelhança, inacessível aos pés de inúmeros e diferentes tamanhos, em um mundo repleto de diversidade.

Consideramos que os resultados nas avaliações em larga escala devam ser relativizados e cuidadosamente analisados. Concordamos, também, com MarinhoAraújo (2004, p. 81-82) quando menciona que "[...] desconstruir uma lógica na qual a 
DOI: http://dx.doi.org/10.7867/1809-0354.2019v14n2p359-381

predominância da padronização, homogeinização, quantificação e comparabilidade objetiva de resultados guiavam os interesses da avaliação demanda esforços políticos, éticos, conceituais". Mesmo considerando aspectos subjetivos da avaliação, acreditamos que é possível fazer dessa força um elemento propulsor de qualidade da IES, dos cursos e da formação estudantil.

A pesquisa aponta que, de acordo com a perspectiva do Sinaes, as potencialidades da instituição de ensino pesquisada referem-se aos indicadores de regime de trabalho do corpo docente, percepções dos estudantes sobre a infraestrutura e processos pedagógicos. As maiores fragilidades são relativas aos indicadores que avaliam proporção de professores doutores nos cursos da IES e desempenho na prova do Enade.

A carência de doutores pode ser compreendida pela dificuldade de acesso à formação, uma vez que, até recentemente, era escassa a oferta de cursos de doutorado na região. Outro fator que justifica a reduzida presença de doutores na IES pesquisada foi a opção de participar de concursos em universidades públicas, no período de ampliação desses contextos. Contudo, mais recentemente, novos quadros foram se formando ou estão em processo de formação. A própria universidade pesquisada aprovou e implantou o primeiro curso de doutorado em 2016 e atualmente aguarda a avaliação de mais três propostas. Acreditamos que o que a instituição pesquisada evidencia em relação ao Sinaes pode ser encontrado noutras instituições de caráter similar, se nos desafiarmos a estudá-las.

A fragilidade no desempenho no Enade é um fator que merece ser aprofundado em novas pesquisas. Nosso estudo nos provoca a compreender o processo de ensino e aprendizagem, não com mero intuito de que o estudante seja bem avaliado no Enade, mas que, por meio dele, a universidade cumpra a sua função de propiciar consistente formação científica, técnica e profissional e contribua com a formação de homens e mulheres comprometidos socialmente, eticamente e politicamente.

\section{JULIANO LUIZ FOSSÁ}

Doutorando em Administração pela Universidade Federal de Santa Catarina - UFSC. 
Atos de Pesquisa em Educação - ISSN 1809-0354

Blumenau, v.14, n.2, p.359-381, mai./ago. 2019

DOI: http://dx.doi.org/10.7867/1809-0354.2019v14n2p359-381

\section{TANIA MARA ZANCANARO PIECZKOWSKI}

Doutora em Educação pela Universidade Federal de Santa Maria - UFSM. Professora e pesquisadora do PPGE - Mestrado em Educação - UNOCHAPECÓ. 
DOI: http://dx.doi.org/10.7867/1809-0354.2019v14n2p359-381

\section{REFERÊNCIAS}

BRASIL. INEP - Instituto Nacional de Estudos e Pesquisas Educacionais Anísio Teixeira. Sinaes - Sistema Nacional de Avaliação da Educação Superior: da concepção à regulamentação. 2. ed. ampl. Brasília: INEP, 2004a.

. Lei n. 10.861, de 14 de abril de 2004. Institui o Sistema Nacional de Avaliação da Educação Superior - Sinaes, e dá outras providências. Diário Oficial da União, Brasília, DF, 15 abr. 2004b.

Ministério da Educação. Portaria normativa n. 40, de 12 de dezembro de $\overline{2007 . ~ I n s t i t u i ~ o ~ e-M E C, ~ s i s t e m a ~ e l e t r o ̂ n i c o ~ d e ~ f l u x o ~ d e ~ t r a b a l h o ~ e ~ g e r e n c i a m e n t o ~ d e ~}$ informações relativas aos processos de regulação, avaliação e supervisão da educação superior no sistema federal de educação, e o Cadastro e-MEC de Instituições e Cursos Superiores e consolida disposições sobre indicadores de qualidade, banco de avaliadores (Basis) e o Exame Nacional de Desempenho de Estudantes (ENADE) e outras disposições. Brasília: Ministério da Educação, 2007.

Portaria normativa $n$. 4, de 06 de agosto de 2008. Regulamenta a aplicação do conceito preliminar de cursos superiores, para fins dos processos de renovação de reconhecimento respectivos, no âmbito do ciclo avaliativo do Sinaes. Diário Oficial da União, Brasília, DF, 2008.

INEP - Instituto Nacional de Estudos e Pesquisas Educacionais Anísio Teixeira. Nota Técnica Daes/Inep n. 58/2015. Brasília: INEP, 2015.

CORREAA, M.; FERRI, C. Enade: um instrumento que avalia (?) qualidade? Curitiba: Apris, 2017.

DIAS SOBRINHO, J. Sobre a proposta do "Sistema de Avaliação do Ensino Superior”. Revista Avaliação, Sorocaba, v. 9, n. 1, 2004.

DMITRUK, H. B. Cadernos metodológicos: diretrizes do trabalho científico. 8. ed. Chapecó: Argos, 2012.

KÖCHE, J. C. Fundamentos de Metodologia Científica: teoria de ciência e iniciação à pesquisa. 20. ed. Petrópolis: Vozes, 2002.

LACERDA, L. L. V.; FERRI, C. Relações entre indicadores de qualidade de ensino e desempenho de estudantes dos cursos de Pedagogia do Brasil no Exame Nacional de Desempenho dos Estudantes. Revista Brasileira de Estudos Pedagógicos, Brasília, v. 96, n. 242, p. 129-145, jan./abr. 2015.

MACHADO, N. S. Prefácio II. In: CORRÊA, M.; FERRI, C. Enade: um instrumento que avalia (?) qualidade? Curitiba: Apris, 2017. p. 13-16. 


\section{Atos de Pesquisa em Educação - ISSN 1809-0354}

\section{Blumenau, v.14, n.2, p.359-381, mai./ago. 2019}

DOI: http://dx.doi.org/10.7867/1809-0354.2019v14n2p359-381

MARINHO-ARAÚJO, C. M. O desenvolvimento de competências no ENADE: a mediação da avaliação nos processos de desenvolvimento psicológico e profissional. Revista da Rede de Avaliação Institucional da Educação Superior, Campinas, v. 9, n. 4, p. 77-97, dez. 2004.

MEYER, D. E.; PARAÍSO, M. A. Metodologias de pesquisas pós-críticas ou sobre como fazemos nossas investigações. In: (Orgs.). Metodologias de pesquisas pós-críticas em educação. Belo Horizonte: Mazza, 2012. p. 15-22.

MINAYO, M. C. S. O desafio do conhecimento: pesquisa qualitativa em saúde. 12. ed. São Paulo: Hucitec, 2012.

PIECZKOWSKI, T. M. Z. Inclusão de estudantes com deficiência na educação superior: efeitos na docência universitária. 2014. 208 f. Tese (Doutorado em Educação) - Universidade Federal de Santa Maria, Santa Maria, 2014.

RISTOFF, D. I. O Sinaes e seus desafios. Revista Avaliação, Sorocaba, v. 9, n. 1, p. 179-183, mar. 2004.

VERHINE, R. E. Avaliação e regulação da educação superior: uma análise a partir dos primeiros 10 anos do Sinaes. Revista Avaliação, Sorocaba, v. 20, n. 3, p. 603619, nov. 2015. 